\title{
Manufacturing and measuring investigation of crown worm tooth surface
}

\author{
Yonghong CHEN***, Yan CHEN*, Jinge WANG* and Guanghui ZHANG** \\ * School of Mechanical Engineering \& Automation, Xihua University \\ 999\# Jin Zhou Rd. Jin niu District, Chengdu, Sichuan Province, China \\ E-mail: chenyonghongjc@163.com \\ ** State Key Laboratory of Mechanical Transmissions, Chongqing University \\ 174 Center Street, District sand, Shapingba, Chongqing, China
}

\section{Received 28 August 2014}

\begin{abstract}
The crown worm drive is a new type of worm drive, it is consisting of an internal gear and a crown worm generating by the internal gear surface, and it is characterized with small size yet high-loading capacity. To satisfy the high precision requirement of crown worm tooth surface, a grinding method based on virtual center distance manufacturing principle is proposed and a grinding machine is reformed. A mathematical model was derived to calculate the theoretical probe center surface, and a measuring method is proposed to check the accuracy of crown worm tooth surface. A crown worm sample is manufactured and measured, the results show that the accuracy is $0.079 \mathrm{~mm}$ on the upside tooth surface and $0.082 \mathrm{~mm}$ on the underside tooth surface. The study is expected to provide the experimental foundation for the future application of the crown worm drive.
\end{abstract}

Key words : Crown worm, Tooth surface, Manufacturing, Measuring

\section{Introduction}

Worm drive is characterized with big transmission ratio, compact structure, low noise and self-locking. It is a necessary part of the machinery industry and the base component industry, and is widely used to transmit motion and power at the shaft angle of $90^{\circ}$.

Worm drive is usually classed as three large classes based on the worm shape, namely the cylinder worm drive with the cylinder-shaped worm (Fig. 1), the spiroid worm drive with cone-shaped worm (Fig. 2) and the hourglass worm drive with hourglass-shaped worm (Fig. 3). The cylinder worm drive includes the ZA worm drive, the ZI worm drive, the ZK worm drive and the ZC worm drive(Buckingham 1949; Shreehah and Abdullah 2006). The spiroid worm drive includes the involute spiroid worm drive and helicon worm drive. The hourglass worm drive includes the Hindley worm drive(Buckingham 1949; Dong 2004; Litvin and Fuentes 2004; Mohan and Shunmugam 2009), the Wildhaber worm drive(Buckingham 1949; Wildhaber 1966), the planar double-enveloping worm drive(Sakai, Maki et al. 1978; Zhang 1978), the toroidal involute worm drive(Wang, Zhan et al. 2002), double-roller enveloping worm drive(Deng, Wang et al. 2012), the integrated toroidal drive(Xu, Huang et al. 2003; Xu, Huang et al. 2004; Xu and Huang 2005; Yao, Dai et al. 2005; Xu and Liu 2012) and the dual-torus double-enveloping toroidal worm drive(Zhao, Su et al. 2010; Zhao and Zhang 2010; Zhao and Zhang 2013).

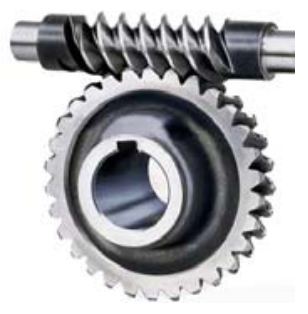

Fig. 1 Cylinder worm drive

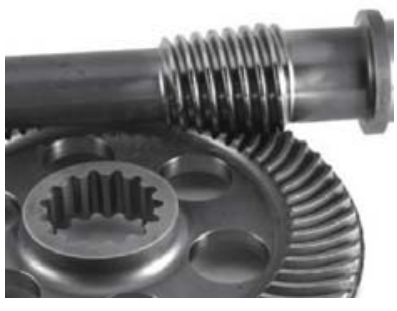

Fig. 2 Spiroid worm drive

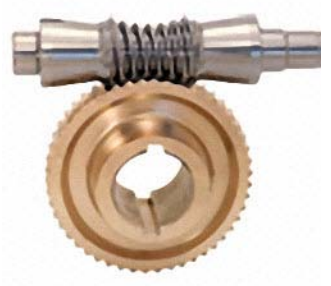

Fig. 3 Hourglass worm drive 
Another class of novel worm drive, which with the drum-shaped worm and is named as crown worm drive (Fig. 4), is proposed recently. The crown worm drive is consisting of an internal gear and a drum-shaped crown worm generating by the internal gear surface, and the crown worm is meshed inside of the internal gear. As the enveloping worm drive, the crown worm is similar with the hourglass worm drive and is also characterized with multi-tooth line contact, good lubrication condition and high-loading capacity. Furthermore, the crown worm drive presents a shorter center distance, lighter weight and more compact structure, benefits of its internal meshing. Shigeru HOYASHITA (HOYASHITA 1996) proposed a calculation method of the cutting edge profile of a barrel-shaped worm conjugate to an internal gear, and confirmed that the regular generating point between the barrel-shaped worm tool and the internal gear is identical with that between the cylinder-shaped worm and the internal gear. PAY Gábor László (László and Sándor 2003; László 2007; László and PAY 2012) investigated the internal worm drive, which is consisting of an internal gear and an ellipsoid worm generating by the cutting edge, and the mathematical modeling was derived, the computer simulation was presented, as well as the manufacturing technology about the ellipsoid worm hob and the internal gear were developed. However, as a novel worm tooth surface(Chen, Zhang et al. 2013), the existing manufacturing and measuring methods for the cylindrical helicoids and hourglass helicoids are not suitable for the crown worm tooth surface(Abdullah and Shreehah 2005).

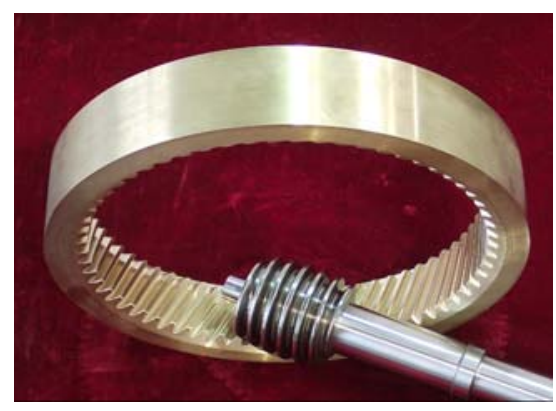

Fig. 4 Crown worm drive

In this study, the planar internal gear enveloping crown worm drive is investigated. The mathematical model of crown worm is developed based on the gear meshing theory, a virtual center distance manufacturing principle is proposed and a special grinding machine is reformed to manufacture the crown worm tooth surface, and a measuring method is proposed to check the accuracy of crown worm tooth surface. The crown worm sample is manufactured and measured.

\section{Generating of crown worm tooth surface}

The follow analyses are based on the hypothesis: the planar internal gear tooth surface $\Sigma^{\mathrm{g}}$ is known, while the crown worm tooth surface $\Sigma^{\mathrm{w}}$ is to be derived.

The crown worm tooth surface is generated by the planar internal gear tooth surfaces, and the coordinate systems in the enveloping process are shown in Fig. 5. The coordinate systems $\sigma_{1}\left(o_{1}: x_{1}, y_{1}, z_{1}\right)$ and $\sigma_{2}\left(o_{2}: x_{2}, y_{2}, z_{2}\right)$ are the fixed coordinate system, which indicate the initial position of the crown worm and the planar internal gear, respectively. The coordinate systems $\sigma_{\mathrm{w}}\left(o_{\mathrm{w}}: x_{\mathrm{w}}, y_{\mathrm{w}}, z_{\mathrm{w}}\right)$ and $\sigma_{\mathrm{g}}\left(o_{\mathrm{g}}: x_{\mathrm{g}}, y_{\mathrm{g}}, z_{\mathrm{g}}\right)$ are the movable coordinate system, which are rigidly connected to the crown worm and the planar internal gear, respectively. The angular velocity of crown worm and planar internal gear are $\omega_{\mathrm{w}}$ and $\omega_{\mathrm{g}}$, respectively. The angular displacement of crown worm and planar internal gear are $\varphi_{\mathrm{w}}$ and $\varphi_{\mathrm{g}}$, respectively. The center distance of the crown worm drive is $a$, and the crossing angle between the crown worm axes and planar internal gear axes is $\delta$. The coordinate system $\sigma_{\mathrm{a}}\left(o_{\mathrm{a}}: x_{\mathrm{a}}, y_{\mathrm{a}}, z_{\mathrm{a}}\right)$ is the auxiliary coordinate system, and the generating plane $x_{\mathrm{a}} o_{\mathrm{a}} z_{\mathrm{a}}$ also is the tooth surface of planar internal gear. The origin $o_{\mathrm{a}}$ is always on the main basic circle, which with the radius $r_{\mathrm{b}}$. The inclination angle of the generating plane is $\beta$. 


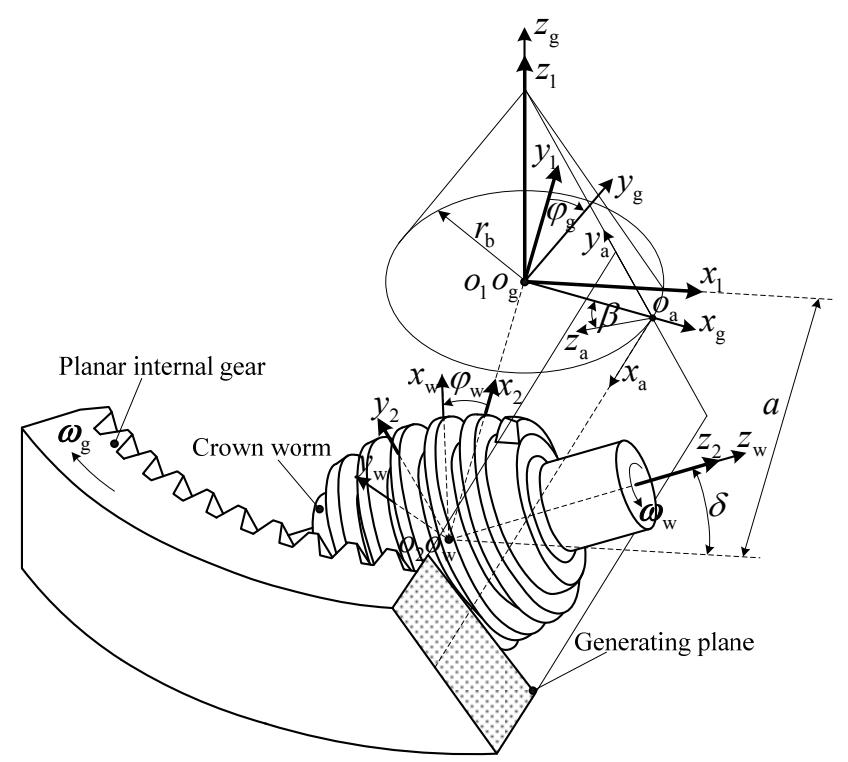

Fig. 5 Coordinate systems

As shown in Fig. 5, the vector equation of planar internal gear tooth surface can be represented in coordinate system $\sigma_{\mathrm{g}}$ as follows:

$$
\boldsymbol{r}^{\mathrm{g}}(u, v)=\left[\begin{array}{lll}
x_{\mathrm{g}}^{\mathrm{g}} & y_{\mathrm{g}}^{\mathrm{g}} & z_{\mathrm{g}}^{\mathrm{g}}
\end{array}\right]^{\mathrm{T}}=\left[\begin{array}{lll}
r_{\mathrm{b}}-v \sin \beta & -u & v \cos \beta
\end{array}\right]^{\mathrm{T}}
$$

Where $u$ and $v$ are the surface parameters of the planar internal gear tooth surface $\Sigma^{\mathrm{g}}$.

Without losing generality, the angular velocity of crown worm can be assumed as that $\omega_{\mathrm{w}}=1 \mathrm{rad} / \mathrm{s}$, and then the angular velocity of planar internal gear is that $\omega_{\mathrm{g}}=1 / i_{12} \mathrm{rad} / \mathrm{s}$. The relative velocity vector $\boldsymbol{v}^{\mathrm{gw}}$ at the meshing point can be represented coordinate system $\sigma_{\mathrm{a}}$ as follows:

$$
\boldsymbol{v}^{\mathrm{gw}}\left(\varphi_{\mathrm{g}}\right)=\left[\begin{array}{lll}
v_{x \mathrm{a}}^{\mathrm{gw}} & v_{y \mathrm{a}}^{\mathrm{gw}} & v_{z \mathrm{a}}^{\mathrm{gw}}
\end{array}\right]^{\mathrm{T}}
$$

Where $v_{x \mathrm{a}}^{\mathrm{gw}}=r_{\mathrm{b}} \sin \delta-a \sin \delta \sin \varphi_{\mathrm{g}}-v \sin \beta \sin \delta-v \cos \beta \cos \delta \cos \varphi_{\mathrm{g}}+\left(r_{\mathrm{b}}-v \sin \beta\right) / i_{12}$

$$
\begin{aligned}
v_{y \mathrm{a}}^{\mathrm{gw}}= & r_{\mathrm{b}} \cos \beta \cos \delta \sin \varphi_{\mathrm{g}}+a \sin \beta \sin \delta \cos \varphi_{\mathrm{g}}-a \cos \beta \cos \delta+u \sin \beta \sin \delta \\
& +u \cos \beta \cos \delta \cos \varphi_{\mathrm{g}}+(u \sin \beta) / i_{12} \\
v_{z \mathrm{a}}^{\mathrm{gw}}= & -r_{\mathrm{b}} \sin \beta \cos \delta \sin \varphi_{\mathrm{g}}+a \cos \beta \sin \delta \cos \varphi_{\mathrm{g}}+a \sin \beta \cos \delta+u \cos \beta \sin \delta \\
& -u \sin \beta \cos \delta \cos \varphi_{\mathrm{g}}+v \cos \delta \sin \varphi_{\mathrm{g}}+(u \cos \beta) / i_{12}
\end{aligned}
$$

The unit normal vector of the generating plane can be represented in coordinate system $\sigma_{\mathrm{a}}$ as following:

$$
\boldsymbol{n}^{\mathrm{g}}=\left[\begin{array}{lll}
n_{x \mathrm{a}}^{\mathrm{g}} & n_{y \mathrm{a}}^{\mathrm{g}} & n_{z \mathrm{a}}^{\mathrm{g}}
\end{array}\right]^{\mathrm{T}}=\left[\begin{array}{lll}
0 & 0 & 1
\end{array}\right]^{\mathrm{T}}
$$

Based on the gear meshing theory(Litvin and Fuentes 2004), for the planar internal gear tooth surface $\Sigma^{\mathrm{g}}$ and the crown worm tooth surface $\Sigma^{\mathrm{w}}$, the meshing equation should be satisfied as following:

$$
\Phi=v^{\mathrm{gw}} n^{\mathrm{g}}=0
$$

Substituting the relative velocity vector $\boldsymbol{v}^{\mathrm{gw}}$ and the unit normal vector $\boldsymbol{n}^{\mathrm{g}}$ into Eq. (4) with Eqs. (2) and (3), the meshing function can be obtained as following:

$$
\begin{aligned}
\Phi\left(u, v, \varphi_{\mathrm{g}}\right)= & v \cos \delta \sin \varphi_{\mathrm{g}}+\left(\cos \beta \sin \delta-\sin \beta \cos \delta \cos \varphi_{\mathrm{g}}-\cos \beta / i_{12}\right) u+ \\
& \left(\sin \beta \cos \delta-\cos \beta \sin \delta \cos \varphi_{\mathrm{g}}\right) a-r_{\mathrm{b}} \sin \beta \cos \delta \sin \varphi_{\mathrm{g}}
\end{aligned}
$$


The crown worm tooth surface $\Sigma^{\mathrm{w}}$ is generated as an enveloping about a series of planar internal gear surfaces $\Sigma^{\mathrm{g}}$. Therefore, using Eqs. (1) and (5), and transforming the contact lines to the coordinate system $\sigma_{\mathrm{w}}$, the vector equation of crown worm tooth surface can be represented as following:

$$
\boldsymbol{r}^{\mathrm{w}}\left(u, v, \varphi_{\mathrm{g}}\right)=M_{2 \mathrm{w}}\left(\varphi_{\mathrm{w}}\right) M_{12} M_{\mathrm{g} 1}\left(\varphi_{\mathrm{g}}\right) \boldsymbol{r}^{\mathrm{g}}(u, v), \Phi\left(u, v, \varphi_{\mathrm{g}}\right)=0
$$

Where $\varphi_{\mathrm{w}}=i_{12} \varphi_{\mathrm{g}}$

$$
M_{2 \mathrm{w}}\left(\varphi_{\mathrm{w}}\right)=\left[\begin{array}{cccc}
\cos \varphi_{\mathrm{w}} & \sin \varphi_{\mathrm{w}} & 0 & 0 \\
-\sin \varphi_{\mathrm{w}} & \cos \varphi_{\mathrm{w}} & 0 & 0 \\
0 & 0 & 1 & 0 \\
0 & 0 & 0 & 1
\end{array}\right], M_{12}=\left[\begin{array}{cccc}
0 & 1 & 0 & a \\
-\sin \delta & 0 & \cos \delta & 0 \\
\cos \delta & 0 & \sin \delta & 0 \\
0 & 0 & 0 & 1
\end{array}\right], M_{\mathrm{g} 1}\left(\varphi_{\mathrm{g}}\right)=\left[\begin{array}{cccc}
\cos \varphi_{\mathrm{g}} & \sin \varphi_{\mathrm{g}} & 0 & 0 \\
-\sin \varphi_{\mathrm{g}} & \cos \varphi_{\mathrm{g}} & 0 & 0 \\
0 & 0 & 1 & 0 \\
0 & 0 & 0 & 1
\end{array}\right]
$$

\section{Manufaturing of crown worm tooth surface}

As a novel worm, the manufacturing method of crown worm is different from that of hourglass worm, and the existing machine can not manufacture the tooth surface of crown worm.

The crown worm tooth surface can be formed by the a planar grinding wheel, which is identical with the tooth surface of the planar internal gear, and the forming principle can be shown in Fig. 6. In Fig.6, the planar grinding wheel is always tangent to the main basic circular cone, and the basic circular cone is a virtual graph, which is formed by the basic circle $r_{\mathrm{b}}$ and the inclination angle $\beta$. The $\omega_{\mathrm{p}}$ is the rotating angular velocity of planar grinding wheel, and the meaning of the other symbols are the same as those in Fig. 5.

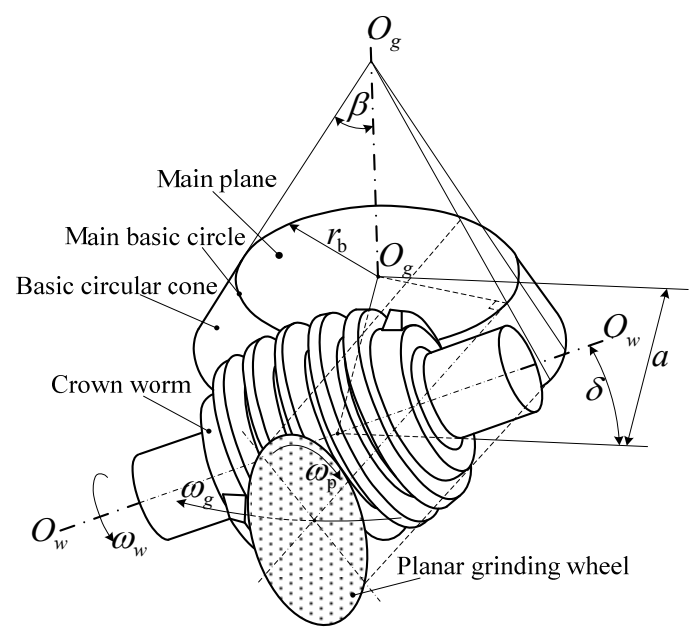

Fig. 6 Forming principle of crown worm

From Fig. 6, it can be known that in order to manufacture the crown worm tooth surface, there should be two rotation motions with crossing angle, and the cutter and its rotation center must be located on the both sides of the crown worm. This manufacturing method is different from the manufacturing method of hourglass worm, and the hourglass worm special machine as well as the reformed gear hobbing machine can not satisfy the demands in Fig. 6 . To solve this problem, a new method, which can be named as virtual center distance manufacturing principle, is proposed based on the theory of rigid body motion. Comparing with the conventional rotation manufacturing principle of the actual rotation center, the virtual center distance manufacturing principle is of the virtual rotation center, as well as one rotation motion and two rectilinear motions synthesized the needed rotation motion.

In the main plane, the rotation motion of planar grinding wheel can be seen as a straight-line $N_{1} N_{2}$ is rotating about point $o_{1}$ with $\omega_{\mathrm{g}}$ and always tangent to the main basic circle, as shown in Fig. 7(a). In Fig. 7(a), the $\varphi_{1}$ and $\varphi_{2}$ are the angle parameters of the point $M$ and the straight-line $N_{1} N_{2}$, the $x_{\mathrm{M}}$ and $y_{\mathrm{M}}$ are the positional parameters of the point $M$, as well as $r_{\mathrm{M}}$ the is the radius of arc $\overparen{m n}$. Based on the theory of rigid body motion, the rotational motion of $N_{1} N_{2}$ 
rotates about point $O_{1}$ can be decomposed into the rotational motion of the $N_{1} N_{2}$ rotates about point $M$ and the translational motion of the $N_{1} N_{2}$ moves along the arc $\overparen{m n}$. The kinematics relation can be represented as following:

$$
\omega_{g}=f\left(\varphi_{1}, \varphi_{2}\right)=f\left(\varphi_{1}, x_{\mathrm{M}}, y_{\mathrm{M}}\right)
$$

An random point $N$ in the straight-line $N_{1} N_{2}$, the velocity relationship can be shown in Fig. 7(b). In Fig. 7(b), the $\omega_{\mathrm{M}}$ and $\omega_{\mathrm{b}}$ are the angular velocity of $o_{1} M$ and $M N$, respectively. The $\boldsymbol{v}_{\mathrm{M}}$ and $\boldsymbol{v}_{\mathrm{N}}$ are translational velocity of point $M$ and point $N$, respectively. Based on the speed synthesis theorem, the following vector relations can be obtained:

$$
\boldsymbol{v}_{\mathrm{N}}=\boldsymbol{v}_{\mathrm{M}}+\omega_{\mathrm{b}} \times \boldsymbol{r}_{\mathrm{NM}}
$$

The $\boldsymbol{v}_{\mathrm{N}}$ is the absolute velocity, and it can be represented as:

$$
\boldsymbol{v}_{\mathrm{N}}=\omega_{\mathrm{g}} \times \boldsymbol{r}_{\mathrm{N}}
$$

The $v_{\mathrm{M}}$ is the convected velocity, and it can be represented as:

$$
\boldsymbol{v}_{\mathrm{M}}=\omega_{\mathrm{M}} \times \boldsymbol{r}_{\mathrm{M}}
$$

Substituting $\boldsymbol{v}_{\mathrm{N}}$ and $\boldsymbol{v}_{\mathrm{M}}$ into Eq. (8) with Eqs. (9) and (10), the vector relations can be obtained as following:

$$
\boldsymbol{\omega}_{\mathrm{g}} \times \boldsymbol{r}_{\mathrm{N}}=\boldsymbol{\omega}_{\mathrm{M}} \times \boldsymbol{r}_{\mathrm{M}}+\boldsymbol{\omega}_{\mathrm{B}} \times \boldsymbol{r}_{\mathrm{NM}}
$$

From Fig. 7(b), the following position vector relations can be obtained:

$$
\boldsymbol{r}_{\mathrm{N}}=\boldsymbol{r}_{\mathrm{M}}+\boldsymbol{r}_{\mathrm{NM}}
$$

By solving the Eqs. (11) and (12) simultaneously, the following results can be determined:

$$
\omega_{\mathrm{g}}=\omega_{\mathrm{M}}=\omega_{\mathrm{b}}
$$

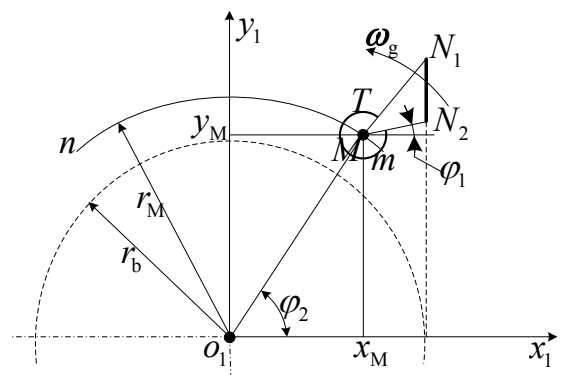

(a) Synthesis of motion

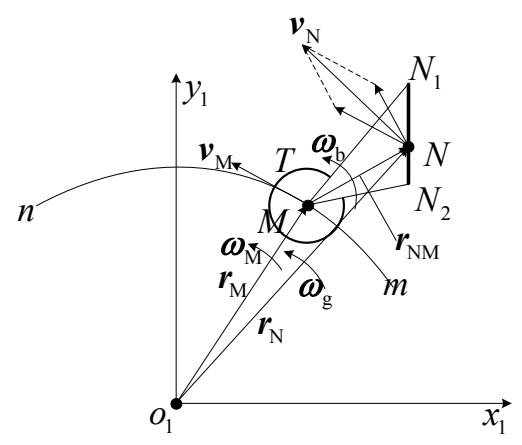

(b) Synthesis of velocity

Fig. 7 Synthesis of rigid body motion

Based on the aforementioned relationships, the virtual center distance manufacturing principle for the crown worm tooth surface is proposed, as shown in Fig. 8. In Fig. 8, the point $M$ is the workbench rotation axis, the point $N$ is a random point on the work surface of planar grinding wheel, the $M_{\mathrm{t}}$ and $N_{\mathrm{t}}$ are the instantaneous positions of point $M$ and point $N$ at time $t$, respectively. The $A$ and $B$ are the rotational motions of workbench and crown worm, respectively. The $\omega_{\mathrm{w}}$ and $\omega_{\mathrm{b}}$ the are the angular velocity vectors of workbench and crown worm, respectively. The $X$ and $Y$ are the rectilinear motion of the workbench, and the $\boldsymbol{v}_{\mathrm{X}}$ and $\boldsymbol{v}_{\mathrm{Y}}$ the are the velocity vectors of the workbench along the $X$ and $Y$, respectively. The $\omega_{\mathrm{p}}$ is the angular velocity vector of the planar grinding wheel.

In order to manufacture the crown worm tooth surface, the following kinematics relation should be satisfied: 


$$
\left\{\begin{array}{l}
\frac{\omega_{\mathrm{w}}}{\omega_{\mathrm{g}}}=i_{12} \\
\omega_{\mathrm{b}}=\omega_{\mathrm{g}} \\
\boldsymbol{v}_{\mathrm{X}}+\boldsymbol{v}_{\mathrm{Y}}=\omega_{\mathrm{g}} \times r_{\mathrm{og}_{\mathrm{g}} \mathrm{M}}
\end{array}\right.
$$

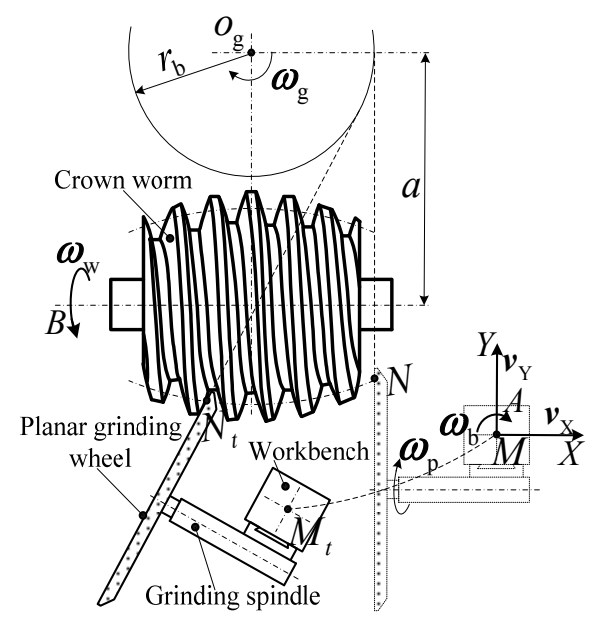

Fig. 8 Virtual center distance manufacturing principle

Based on the virtual center distance manufacturing principle of the crown worm tooth surface(Fig. 8), a NC lathe is modified to the crown worm special grinding machine, as shown in Fig. 9. The headstock was placed with the inclination angle of $\delta$, and the crossing angle between the planar grinding wheel and the plumb position is $\beta$. This special grinding machine has four numerically closed-loop controlled axes: the longitudinal rectilinear motion $X$ about the workbench, the transversal rectilinear motion $Y$ about the workbench, the rotational motion $A$ about the workbench and rotational motion $B$ about the crown worm. According to the Eq. (14), the kinematics relation of the four motion axes can be determined.

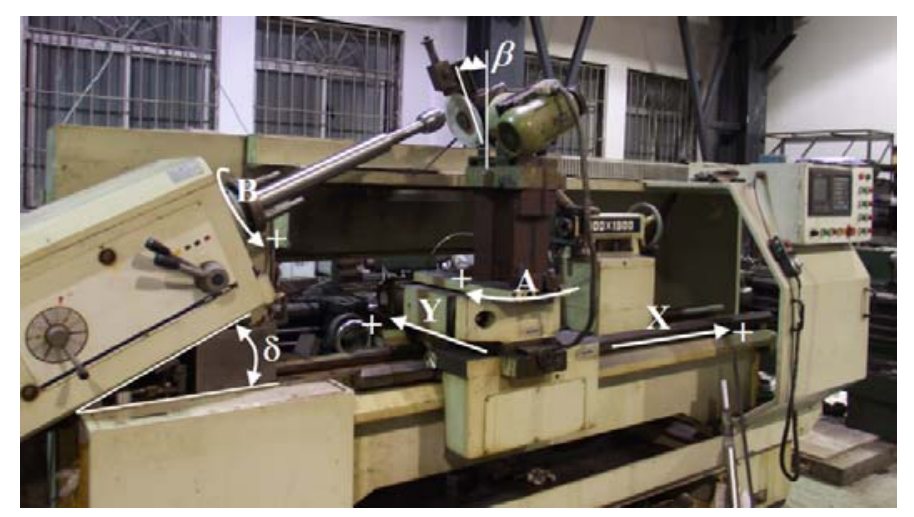

Fig. 9 Crown worm special grinding machine

According to the major design parameters of planar internal gear enveloping crown worm drive shown in Table 1, the tooth surface of crown worm sample is ground on the crown worm special grinding machine, as shown in Fig. 10. The crown worm sample with ground tooth surface is shown in Fig. 11. 
Yonghong Chen, Yan Chen, Wang and Zhang,

Journal of Advanced Mechanical Design, Systems, and Manufacturing, Vol.9, No.1 (2015)

Table 1 Design parameters

\begin{tabular}{lc}
\hline \hline \multicolumn{1}{c}{ Parameters } & Values \\
\hline Center distance, $a(\mathrm{~mm})$ & 100 \\
Number of crown worm threads, $Z_{1}$ & 1 \\
Number of planar internal gear teeth, $Z_{2}$ & 63 \\
Thread direction & Right \\
Axes crossing angle, $\delta\left(^{\circ}\right)$ & 25 \\
Inclination angle of generating plane, $\beta\left(^{\circ}\right)$ & 28 \\
Radius of main basic circle, $r_{\mathrm{b}}($ mm $)$ & 45 \\
Reference radius of the crown worm at its umbilicus, $r_{1}(\mathrm{~mm})$ & 35 \\
\hline
\end{tabular}

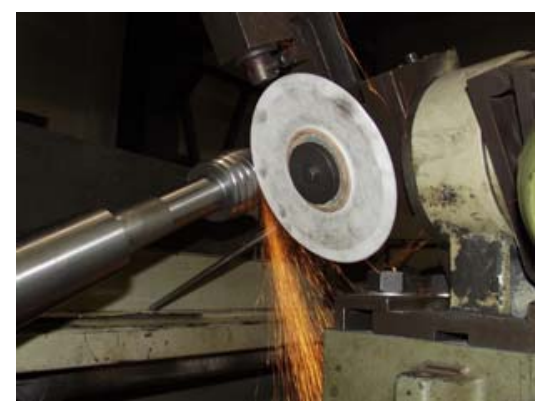

(a) Right flank

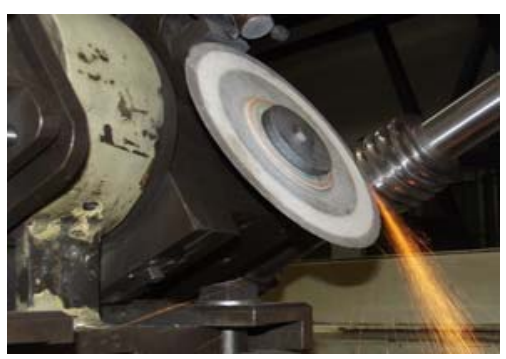

(b) Left flank

Fig. 10 Grinding of crown worm tooth surface

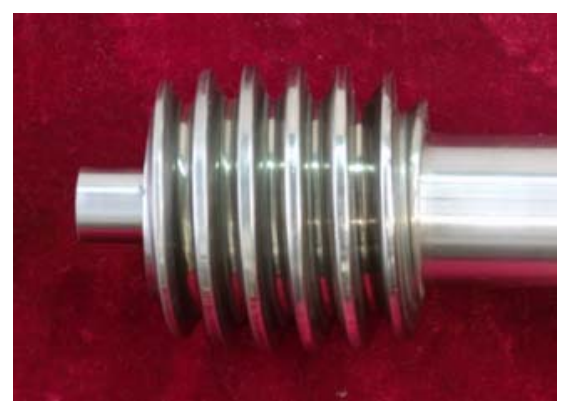

Fig. 11 Sample of crown worm

\section{Measuring of crown worm tooth surface}

In contrast to cylindrical worm and hourglass worm, for crown worm no practical possibility for a reliable metrological traceability to national or international measurement standards can be provided. And the automatic measuring devices and evaluation software cannot directly measure the accuracy of crown worm tooth surface(S, Y et al. 2001, Goch 2003, Mohan and Shunmugam 2005, Liu, Chen et al. 2012, Guenther, Kniel et al. 2013).

While cylindrical worms can be described precisely by their tooth profile, helix and pitch parameters, crown worm is numerically defined solely by differential geometric approaches. Only by viewing the discrete points of a generated pattern covering both sides of crown worm tooth surface, the quality of the measured object can be assessed by a nominal-actual comparison. Therefore, the crown worm measurement is referred to as a free-form measurement, and the errors can be defined as shown in Fig. 8. In Fig. 12, the $\Sigma^{\mathrm{w}}$ is the theoretical crown worm tooth surface, the $\Sigma^{\mathrm{w}}$ is the actual crown worm tooth surface, the $\Delta f_{\mathrm{s}}$ is the error of each measure point. The error $\Delta f_{\mathrm{s}}$ is defined as the normal 
distance between the measured point in $\Sigma^{w^{\prime}}$ and the corresponding point in $\Sigma^{\mathrm{w}}$. And the error $\Delta f_{\mathrm{s}}$ has a positive value while the $\Sigma^{w^{\prime}}$ is bulged out of the $\Sigma^{\mathrm{w}}$, otherwise, the error $\Delta f_{\mathrm{s}}$ has a negative value.

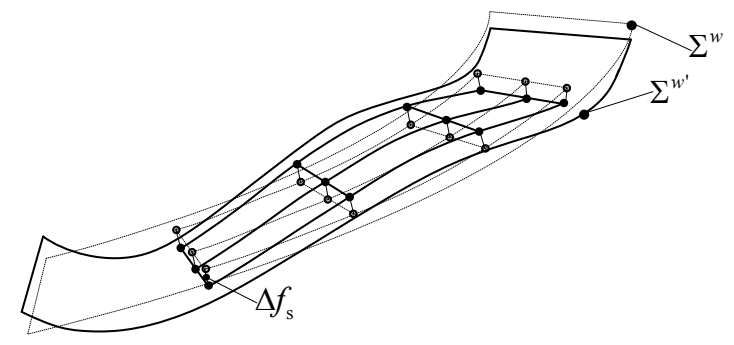

Fig. 12 Geometrical model of errors

In order to acquire the errors of the crown worm tooth surface, the following steps need to be done.

(1) Data acquisition

The CNC-controlled gear measuring instrument with the function of contour scanning is used to acquire the points data, as shown in Fig. 13. In Fig. 13, $C$ is the rotational motion of crown worm, $X, Y$ and $Z$ are the rectilinear motion of probe. The points data of crown worm tooth surface can be acquired by the steps as following:

Firstly, locking the rectilinear motion of $Z$, and measuring three points on the reference circle I. The coordinate values about the center of reference circle can be calculated and represented as $\left(x_{\mathrm{c}}{ }^{(\mathrm{I})}, y_{\mathrm{c}}{ }^{(\mathrm{I})}, z_{\mathrm{c}}{ }^{(\mathrm{I})}\right)$. $z_{\mathrm{c}}^{(\mathrm{II})}$.

Secondly, measuring a point on the reference plane II, and the coordinate values can be represented as $\left(x_{\mathrm{c}}{ }^{(I I)}, y_{\mathrm{c}}{ }^{(\mathrm{II})}\right.$,

Finally, locking the rectilinear motion of $X$ and the rotational motion of $C$, measuring the tooth profile points III through control the rectilinear motion of $Y$ and $Z$. A series of tooth profile points can be measured by control the rotational motion of $C$, and the coordinate values of these tooth profile points can be represented as $\left(x_{\mathrm{c}}{ }^{(\mathrm{III})}, y_{\mathrm{c}}{ }^{\text {(III) }}, z_{\mathrm{c}}{ }^{\text {(III) }}\right)$. Here, the superscript $k$ is the code number of measured points.

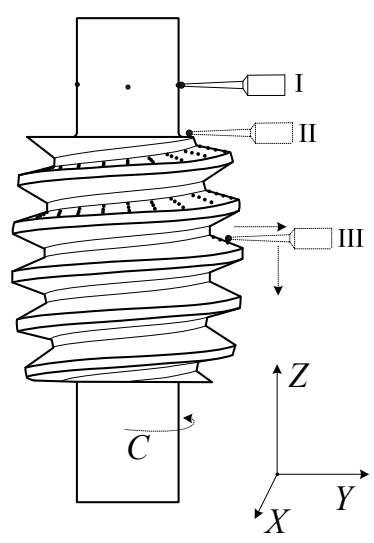

Fig. 13 Acquire the points data

\section{(2) Probe radius compensation}

The points data acquired by the CNC-controlled gear measuring instrument are the probe center data, rather than the surface point data of the crown worm. It, thus, becomes a need to compensate the probe radius before the measured points data can be used. The probe radius compensate method of "produce the offset theoretical probe center surface" can be used in the crown worm measuring(Liang and Lin 2002).

According to the Eq. (3) and coordinate transformation, the unit normal vector of crown worm tooth surface $\Sigma^{\mathrm{w}}$ can be represented in coordinate system $\sigma_{\mathrm{w}}$ as following: 


$$
\boldsymbol{n}^{\mathrm{w}}\left(\varphi_{\mathrm{g}}\right)=M_{2 \mathrm{w}}\left(\varphi_{\mathrm{w}}\right) M_{12} M_{\mathrm{g} 1}\left(\varphi_{\mathrm{g}}\right) \boldsymbol{n}^{\mathrm{g}}
$$

The theoretical probe center surface can be represented in coordinate system $\sigma_{\mathrm{w}}$ as following:

$$
\boldsymbol{r}^{c}=\boldsymbol{r}^{\mathrm{w}}\left(u, v, \varphi_{\mathrm{g}}\right)+r_{\mathrm{p}} \boldsymbol{n}^{w}\left(\varphi_{\mathrm{g}}\right)
$$

Where $r_{\mathrm{p}}$ is the radius of probe.

\section{(3) Tooth profile match}

Eq. (16) shows that the theoretical probe center surface is in the theoretical coordinate system $\sigma_{\mathrm{w}}$, but the measured points data are in the instrument coordinate system $\sigma_{\mathrm{c}}$. In order to compare the measured points data and the data of theoretical probe center surface, it should transformation them into the same coordinate system, and the transformation method is shown in Fig. 14.

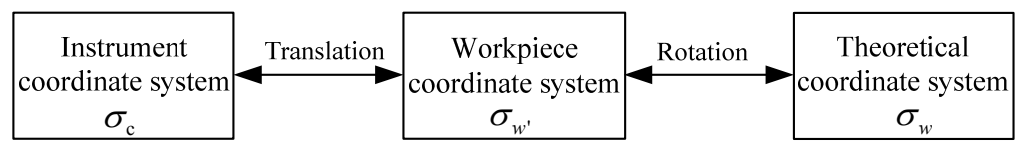

Fig. 14 Transformation of coordinate system

Base on the reference circle I and reference plane II in Fig. 13, the measured points data in instrument coordinate system $\sigma_{\mathrm{c}}$ can be transformed into the theoretical coordinate system $\sigma_{\mathrm{w}}$ by translation and rotation. The coordinate values of measured points can be represented in theoretical coordinate system $\sigma_{\mathrm{w}}$ as following:

$$
\left.\begin{array}{l}
\left(x_{1}^{(\mathrm{a})}\right)^{(k)}=\left(y_{\mathrm{c}}^{(k)} \sin c_{\mathrm{c}}^{(k)}-x_{\mathrm{c}}^{(\mathrm{I})}\right) \cos \varphi_{\mathrm{c}}+\left(y_{\mathrm{c}}^{(k)} \cos c_{\mathrm{c}}^{(k)}-y_{\mathrm{c}}^{(\mathrm{I})}\right) \sin \varphi_{\mathrm{c}} \\
\left(y_{1}^{(\mathrm{a})}\right)^{(k)}=-\left(y_{\mathrm{c}}^{(k)} \sin c_{\mathrm{c}}^{(k)}-x_{\mathrm{c}}^{(\mathrm{I})}\right) \sin \varphi_{\mathrm{c}}+\left(y_{\mathrm{c}}^{(k)} \cos c_{\mathrm{c}}^{(k)}-y_{\mathrm{c}}^{(\mathrm{I})}\right) \cos \varphi_{\mathrm{c}} \\
\left(z_{1}^{(\mathrm{a})}\right)^{(k)}=z_{\mathrm{c}}^{(k)}-\left(z_{\mathrm{c}}^{(\mathrm{I})}-r_{\mathrm{p}}-h\right)
\end{array}\right\}
$$

Here, $h$ is the distance between the reference plane and the center of crown worm, $\varphi_{\mathrm{c}}$ is the match angle.

The corresponding theoretical points in the theoretical probe center surface should be satisfied:

$$
\left.\begin{array}{l}
\left(z_{1}^{(\mathrm{t})}\right)^{(k)}=\left(z_{1}^{(\mathrm{a})}\right)^{(k)} \\
\sqrt{\left(\left(x_{1}^{(\mathrm{t})}\right)^{(k)}\right)^{2}+\left(\left(y_{1}^{(\mathrm{t})}\right)^{(k)}\right)^{2}}=\sqrt{\left(\left(x_{1}^{(\mathrm{a})}\right)^{(k)}\right)^{2}+\left(\left(y_{1}^{(\mathrm{a})}\right)^{(k)}\right)^{2}}
\end{array}\right\}
$$

Here, $\left(x_{1}{ }^{(\mathrm{t})}\right)^{(k)},\left(y_{1}{ }^{(\mathrm{t})}\right)^{(k)}$ and $\left(z_{1}{ }^{(\mathrm{t})}\right)^{(k)}$ are the coordinate values of the corresponding theoretical point, and it can be solved by the Eqs. (16), (17) and (18).

Between the measured point and the corresponding theoretical point, the errors can be represented as:

$$
\left(\Delta f_{\mathrm{s}}\right)^{(k)}=K_{\mathrm{T}} \sin \lambda^{(k)} \sqrt{\left(\left(x_{1}^{(\mathrm{a})}\right)^{(k)}-\left(x_{1}^{(\mathrm{t})}\right)^{(k)}\right)^{2}+\left(\left(y_{1}^{(\mathrm{a})}\right)^{(k)}-\left(y_{1}^{(\mathrm{t})}\right)^{(k)}\right)^{2}}
$$

Here, $\lambda^{(\mathrm{k})}$ is helix angle of each corresponding theoretical point, $K_{\mathrm{T}}$ is determination coefficient of convex or concave. When the $\left(y_{1}{ }^{(\mathrm{a})}\right)^{(k)}>0$ and $\left(x_{1}{ }^{(\mathrm{a})}\right)^{(k)}>\left(x_{1}{ }^{(\mathrm{t})}\right)^{(k)}$, or $\left(y_{1}{ }^{(\mathrm{a})}\right)^{(k)}<0$ and $\left(x_{1}{ }^{(\mathrm{a})}\right)^{(k)}<\left(x_{1}{ }^{(\mathrm{t})}\right)^{(k)}$, the determination coefficient $K_{\mathrm{T}}=1$; otherwise $K_{\mathrm{T}}=-1$.

The actual measured points and the theoretical probe center surface can be matched by the Least-Square Fitting. The match angle $\varphi_{\mathrm{c}}$ is chosen as the variable parameter, and the evaluating function can be defined as:

$$
f_{\mathrm{c}}\left(\varphi_{\mathrm{c}}\right)=\min \sum_{k=1}^{k_{\mathrm{c}}}\left(\left(\Delta f_{\mathrm{s}}\right)^{(k)}\right)^{2}
$$

Here, $k_{\mathrm{c}}$ is the maximum code number of the measured points.

\section{(4) Data processing}

In order to solve the Eq. (20) and calculate the errors of each measured point, the data should be processed as 
shown in Fig. 15. In Fig. 15, $\varphi_{\mathrm{bc}}$ is the step length of match angle $\varphi_{\mathrm{c}}$, and the step-by-step search method is used to search the optimal match angle.

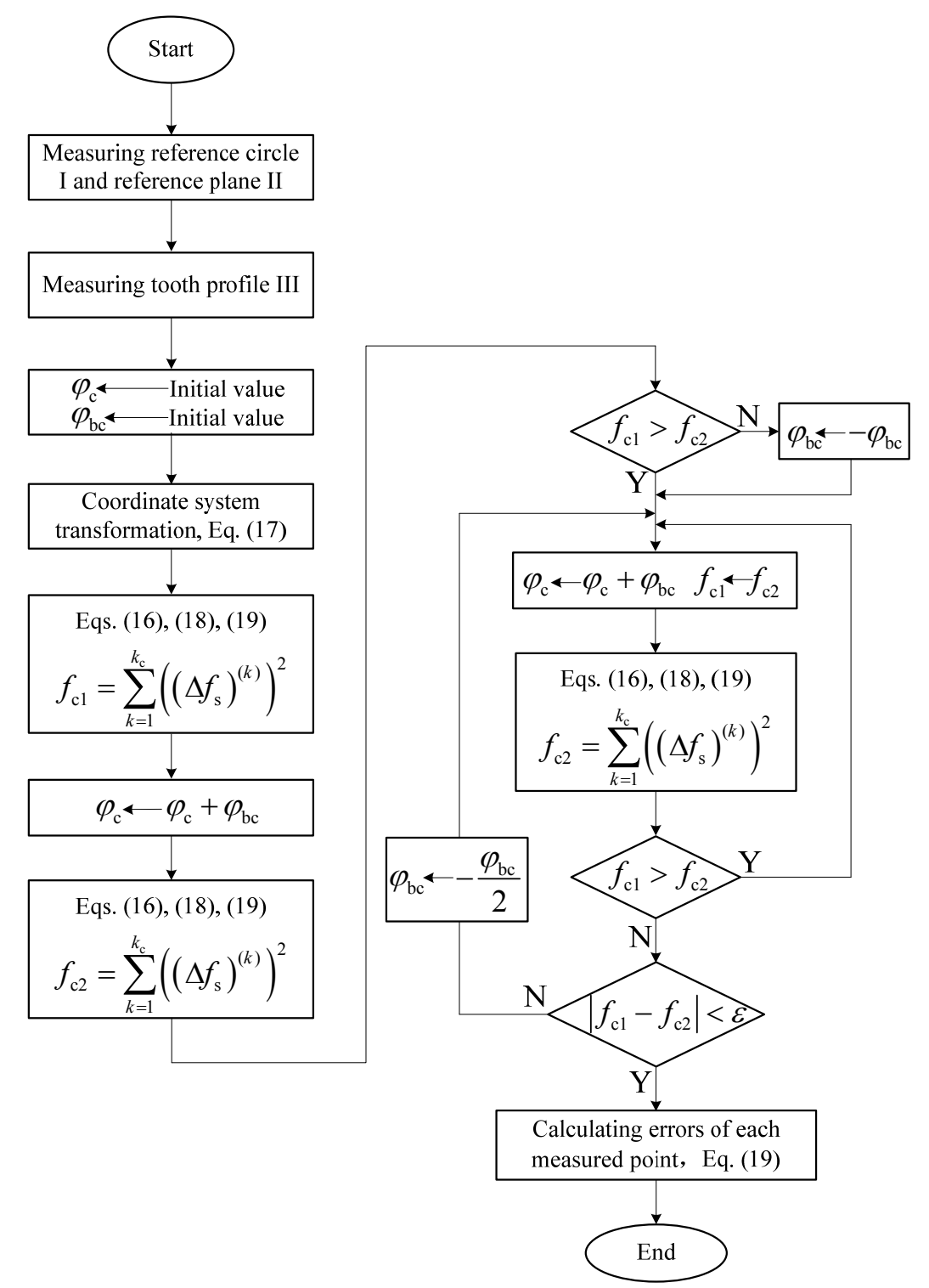

Fig. 15 Flowchart of data processing

The Klingelberg P26 CNC-controlled gear measuring instrument is used to measure the crown worm tooth surface, as shown in Fig.16. The radius of probe $r_{\mathrm{p}}$ is $0.499 \mathrm{~mm}$, through the data processing as shown in Fig. 15, the maximum errors and the minimum errors on the crown worm tooth surface can be calculated as shown in Table 2.

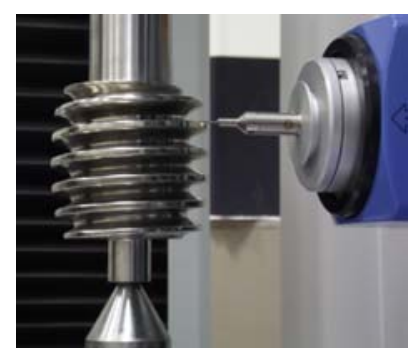

Fig. 16 Measuring of crown worm tooth surface 
Yonghong Chen, Yan Chen, Wang and Zhang,

Journal of Advanced Mechanical Design, Systems, and Manufacturing, Vol.9, No.1 (2015)

Table 2 Errors of crown worm tooth surface

\begin{tabular}{ccccccc}
\hline \hline & \multicolumn{2}{c}{ Upside tooth surface } & & \multicolumn{2}{c}{ Underside tooth surface } \\
\cline { 2 - 3 } \cline { 5 - 6 } & Minimum & Maximum & & Minimum & Maximum \\
\hline \multirow{2}{*}{ Errors $\Delta f_{\mathrm{s}} / \mathrm{mm}$} & -0.027 & 0.052 & & -0.049 & 0.033 \\
\hline
\end{tabular}

\section{Conclusions}

Presented is manufacturing and measuring method of crown worm tooth surface. Based on the performed research, the following conclusions may be drawn:

(1) The mathematical model of crown worm is established based on the gear meshing theory, a virtual center distance manufacturing method is proposed to solve the manufacturing of crown worm tooth surface, as well as the measuring method of crown worm tooth surface is presented.

(2) Through the manufacturing and measuring of crown worm sample, the rightness of virtual center distance manufacturing principle is validated, the feasibility of reformed grinding machine and measuring method are validated.

(3) The accuracy of this crown worm sample is that $0.079 \mathrm{~mm}$ on the upside tooth surface and $0.082 \mathrm{~mm}$ on the underside tooth surface, and this crown worm sample is of high precision.

(4) The manufacturing principle and the reformed grinding machine presented in this paper could be used to manufacture other cylindrical worms, hourglass worms and spiroid worms. The measuring principle also could be used to measure the accuracy of hourglass worm tooth surface.

\section{Acknowledgment}

This work was supported by the National Natural Science Foundation of China (Grant No. 51405394), the Applied Basic Research Program of Sichuan Provincial Science and Technology Department (Grant No. 2014JY0129), the Chun Hui Project (Grant No. Z2014074).

\section{Nomenclature}

a Center distance of crown worm drive, $(\mathrm{mm})$

$Z_{1}, Z_{2} \quad$ Number of the crown worm threads and the planar internal gear teeth, respectively

$r_{\mathrm{b}} \quad$ Radius of the main basic circle, (mm)

$r_{1} \quad$ Reference radius of the crown worm at its umbilicus, (mm)

$\delta \quad$ Axes crossing angle between the planar internal gear and the crown worm, $\left(^{\circ}\right)$

$\beta \quad$ Inclination angle of the generating plane, $\left(^{\circ}\right)$

$i_{12} \quad$ Gearing ratio of the worm drive, here $i_{12}=Z_{2} / Z_{1}$

$\sigma_{1}, \sigma_{2} \quad$ Fixed coordinate systems

$\sigma_{\mathrm{w}}, \sigma_{\mathrm{g}} \quad$ Movable coordinate systems

$\sigma_{\mathrm{a}} \quad$ Auxiliary coordinate system

$\Phi \quad$ Meshing function of crown worm drive

$M_{\mathrm{mn}} \quad$ Matrix for coordinate transformation from $\sigma_{\mathrm{m}}(m=1,2, \mathrm{a}, \mathrm{g}, \mathrm{w})$ to $\sigma_{\mathrm{n}}(m=1,2, \mathrm{a}, \mathrm{g}, \mathrm{w})$

$\boldsymbol{r}^{\mathrm{g}}, \boldsymbol{r}^{\mathrm{w}} \quad$ Position vector of $\Sigma^{\mathrm{g}}$ and $\Sigma^{\mathrm{w}}$, respectively

$\boldsymbol{n}^{\mathrm{g}} \quad$ Unit normal vector of $\Sigma^{\mathrm{g}}$

$\omega_{\mathrm{m}} \quad$ Angular velocity vectors of the planar internal gear $(m=\mathrm{g})$, the crown worm $(m=\mathrm{w})$, the workbench $(m=\mathrm{b})$ and the planar grinding wheel $(m=\mathrm{p})$, respectively, $(\mathrm{rad} / \mathrm{s})$

$\boldsymbol{v}_{\mathrm{x}}, \boldsymbol{v}_{\mathrm{y}} \quad$ Translational velocity vectors of the workbench along $X$ and $Y$, respectively, $(\mathrm{mm} / \mathrm{s})$

$v^{\mathrm{xy}} \quad$ Relative velocity vector between planar internal gear and crown worm, $(\mathrm{mm} / \mathrm{s})$

$\boldsymbol{\varphi}_{\mathrm{g}}, \boldsymbol{\varphi}_{\mathrm{w}} \quad$ Rotating angles of the planar internal gear and the crown worm, respectively, $\left(^{\circ}\right)$

$\Sigma^{\mathrm{g}}, \Sigma^{\mathrm{w}} \quad$ Tooth surface of the planar internal gear and the crown worm, respectively 


\section{References}

Abdullah, R. and Shreehah, T., Finishing the concave shape of the worm thread, Machining Science and Technology, Vol. 9, No. 4(2005), pp.589-599.

Buckingham, E., Analytical mechanics of gears, New York, Mcgraw-hill Book Company,INC., (1949), pp.225-237.

Chen, Y. H., Zhang, G. H., Chen, B. K., Luo, W. J., Li, F. J. and Chen, Y., A novel enveloping worm pair via employing the conjugating planar internal gear as counterpart, Mechanism and Machine Theory, Vol. 67(2013), pp.17-31.

Deng, X. Q., Wang, J. G, Horstemeyer, F., Solanki, N. and Zhang, J. F., Parametric study of meshing characteristics with respect to different meshing rollers of the antibacklash double-roller enveloping worm gear, ASME Journal of Mechine Design, Vol. 134, No. 8(2012), pp.1-12.

Dong, X., Design and modification of hourglass worm drive, Beijing, Machinery Industry Press, (2004), pp.63-78(in Chinese).

Goch, G., Gear Metrology, CIRP Annals - Manufacturing Technology, Vol. 52, No. 2 (2003), pp.659-695.

Guenther, A., Kniel, K., Härtig, F. and Lindner, I., Introduction of a new bevel gear measurement standard, CIRP Annals - Manufacturing Technology, Vol. 62, No.1 (2013), pp.515-518.

Hoyashita, S., Barrel worm-shaped tool with conjugate cutting-edge profile generated from tooth profile of internal gear, Transactions of the Japan Society of Mechanical Engineers, Part C. Vol. 62, No.593(1996), pp.284-290(in Japanese).

László, P., Internal worm gears with no perpendicular axis, 7th International Multidisciplinary Conference, Baia Mare, Romania, (2007), pp.591-596.

László, P. and PAY, E., Special internal worm gear pairs with helical worm, Proceedings in Manufacturing Systems Vol. 7, No.1 (2012), pp.31-36.

László, P. and Sándor, R., Method and new device for ellipsoid worm gear manufacturing on the turning, 5th International Multidisciplinary Conference, Friedrichroda, Germany, (2003), pp. 413-418.

Liang, S. and Lin, A., Probe-radius compensation for 3D data points in reverse engineering, Computers in Industry, Vol. 48 (2002), pp.241-251.

Liu, J. Y., Chen, B., Matsumura, S., Li, C. Y. and Houjoh, H., Design of a novel cycloid drive with a cycloid-arc gear and analysis of its meshing characteristic, Journal of Advanced Mechanical Design Systems and Manufacturing, Vol. 6, No.2 (2012), pp.310-322.

Liu, J. Y, Matsumura, S., Chen, B. K. and Houjoh, H., Torsional stiffness calculation of double-enveloping cycloid drive, Journal of Advanced Mechanical Design Systems and Manufacturing, Vol. 6, No.1(2012), pp.2-14.

Litvin, F. L. and Fuentes, A., Gear geometry and applied theory, second edition, New York, Cambridge University Press, (2004), pp.158-170.

Mohan, L. and Shunmugam, M., An orthogonal array based optimization algorithm for computer-aided measurement of worm surface, International Journal of Advanced Manufacturing Technology, Vol. 30, No. 6 (2005), pp.434-443.

Mohan, L. and Shunmugam, M., Geometrical aspects of double enveloping worm gear drive, Mechanism and Machine Theory, Vol. 44, No. 11 (2009), pp.2053-2065.

Podzharov, E., Selection of geometric parameters of gear and grinding wheel to ensure maximum gear tooth profile accuracy, Machining Science and Technology, Vol. 9, No. 3(2005), pp.369-381.

Sakai, T., Maki, M., Uesugi, S. and Horiuchi, A., A study on hourglass worm gearing with developable tooth surfaces, ASME Journal of Mechine Design, Vol. 100 (1978), pp.451-459.

Shreehah, T. and Abdullah, R., Modification of geometry and technology of cylindrical worms, Machining Science and Technology, Vol. 10, No. 4(2006), pp.539-547.

Wang, S. R, Zhan, D., Liu, H. and Wang, S. Y., Tooth contact analysis of toroidal involute worm mating with involute helical gear, Mechanism and Machine Theory, Vol. 37(2002), pp. 685-691.

Wildhaber, E., Wildhaber worm drive, United States Patent 3386305, (1966).

Wu, D. S., Lai, H. Y. and Chen, C. K., A new approach to enhance the manufacturing accuracy of the cylindrical worm using measured circular-arc helicoidal profile dat, Proceedings of the Institution of Mechanical Engineers, Part B: Journal of Engineering Manufacture, Vol. 215(2001), pp. 47-58.

$\mathrm{Xu}, \mathrm{L} . \mathrm{Z}$. and Huang, J., Torques for electromechanical integrating toroidal drive, Proceedings of the Institution of Mechanical Engineers, Part C: Journal of Mechanical Engineering Science, Vol. 219, No. 8(2005), pp. 801-811. 
Xu, L. Z., Huang, Z. and Yang, Y. L., Contact stress for toroidal drive, ASME Journal of Mechine Design, Vol. 125, No.1 (2003), pp. 165-168.

Xu, L. Z., Huang, Z. and Yang, Y. L., Mesh theory for toroidal drive, ASME Journal of Mechine Design, Vol. 126, No.3(2004), pp.551-557.

Xu, L. Z. and Liu, S. D., Two output ways for electromechanical integrated toroidal drive, Mechanism and Machine Theory, Vol. 47(2012), pp.103-116.

Yao, L. G., Dai, J. S., Wei, G. W. and Li, H. M., Geometric modeling and meshing characteristics of the toroidal drive, ASME Journal of Mechine Design, Vol. 127, No. 5(2005), pp.988-996.

Zhang, G. H., Research and application of planar double-enveloping hourglass worm drive, Journal of Chongqing University, Vol. 1, No. 3 (1978), pp.1-18(in Chinese).

Zhao, Y. P., Su, D. Z. and Zhang, Z., Meshing analysis and technological parameters selection of dual tori double-enveloping toroidal worm drive, Mechanism and Machine Theory, Vol. 45, No. 9(2010), pp. 1269-1285.

Zhao, Y. P. and Zhang Y., Determination of the most dangerous meshing point for modified-hourglass worm drives, ASME Journal of Mechine Design, Vol. 135, No.3 (2013), pp.1-8.

Zhao, Y. P. and Zhang Z., Computer aided analysis on the meshing behavior of a height-modified dual-torus double-enveloping toroidal worm drive, Computer-Aided Design, Vol. 42, No. 12 (2010), pp.1232-1240. 